\title{
A THEORETICAL FRAMEWORK OF THE INFLUENCE OF MOBILITY IN CONTINUED USAGE INTENTION OF SMART MOBILE DEVICE
}

\author{
Vincent Cho and Eric Ngai \\ Department of Management and Marketing, \\ The Hong Kong Polytechnic University, Hong Kong \\ vincent.cho@polyu.edu.hk \\ eric.ngai@polyu.edu.hk
}

\begin{abstract}
In the face of fierce competition in the mobile device market, the only way for smart mobile device producers to maintain and expand their market share is to design and develop products that meet users' expectations. With the increasing importance of smart mobile devices in people's lives, mobility is likely to be a key feature that addresses the needs of mobile phone users. Therefore, this survey investigates mobility in four essential aspects: spatiality, temporality, contextuality, and social fluidity with the purpose of finding mobile device functions that users value highly. Special attention is paid to how these constructs affect continued usage intention (CUI) through two intermediates: user confirmation and user satisfaction.
\end{abstract}

\section{KEYWORDS}

Mobility, continued usage

\section{INTRODUCTION}

With the current boom in information and communication technology (ICT), mobile devices are an indispensable part of people's working and social lives. Mobile devices attend to users' daily routines and assist them in handling contextual tasks and staying current with their social needs. Kakihara and Sorensen (2004) noted that ubiquitous and pervasive mobile technologies manifested themselves at the turn of the millennium. Since then, mobile communication has proven to be desirable to all types of users (Haney, 2005).

Mobility is a key requirement for addressing the needs of mobile phone users. That is to say, users tend to adopt to devices that facilitate mobility as integral parts of their lives. Thus, it would be worthwhile to advance our understanding of how mobility affects continued usage intention of smart phones, which are enabled with either $3 \mathrm{G}$ or $4 \mathrm{G}$ technology.

Mobility traditionally refers to the movement of objects from one location to another, as well as their transformation in terms of state, condition, or structure (Kakihara and Sorensen, 2004). Mobility creates choices and new freedoms for users (Keen and Mackintosh, 2001) and allows users to deal with the environment dynamically. Mobility is a central and primary factor affecting 
continued usage intention of mobile devices (Lee, Kang, \& Kim, 2007). Based on the expectation confirmation theory, once a user experiences using a mobile device and his or her expectations are confirmed, he or she will continue using the device. In this study, we investigate mobility in four essential aspects: spatiality, temporality, contextuality, and social fluidity. We also investigate how these four dimensions affect the CUI of mobile devices.

\section{THEORETICAL FRAMEWORK}

Continued usage of technology is defined as the long-term usage of an innovation or information technology (Bhattacherjee, 2001; Premkumar and Bhattacherjee, 2008). Conceptually, this continuous usage would occur on a regular or ad hoc basis (Meister \& Compeau, 2002). For example, users who habitually book hotels through online reservation web sites, but do not visit these sites regularly, are still considered continuous users. This phenomenon can be regarded as the post-acceptance stage in the innovation diffusion model, wherein users accept a technology, continue using it, and possibly even consider this usage as normal activity (Rogers, 1995; Cooper and Zmud, 1990).

The concept of continued usage has been examined in such contexts as implementation (Zmud, 1983), system survival (Cooper, 1991), incorporation (Kwon \& Zmud, 1987), routinization (Cooper and Zmud, 1990), and infusion (Meister \& Compeau, 2002; Bell, 2004) in the information technology (IT) and information systems (IS) implementation literature. These studies acknowledge the existence of a post-acceptance stage where using an IS technology or service transcends conscious behavior and becomes part of the user's routine activity.

The main stream of research on the continued usage of technology relies on the cognitive dissonance theory, which states that if a person's attitude and behavior are at odds (in a state of dissonance), then that person may change his or her attitude to reduce dissonance (Festinger, 1957). This theory is concerned with the degree to which relevant cognitive elements, such as knowledge, attitudes, and beliefs about the self and the environment, are compatible. In time, the cognitive dissonance theory evolved into the expectation-disconfirmation-satisfaction paradigm, which in turn gave rise to the expectation disconfirmation theory (EDT) (Oliver, 1980; Bhattacherjee, 2001). EDT was specifically designed to explain post-adoption behavior following one's first-hand experience with the target system. It is a process model that utilizes users' backward-looking perspectives or retrospective perceptions to explain their intentions and behaviors based on their initial expectations and their actual usage experience, which includes confirmation and satisfaction. Confirmation refers to a customer's evaluation or judgment of the performance of a service or technology as compared to a pre-purchase comparison standard. Moreover, user satisfaction is a pleasurable, positive emotional state resulting from a specific experience (Locke, 1976; Wixom and Todd, 2005). In this context, satisfaction is an affective state representing an emotional reaction to the usage of a technology (Oliver, 1992; Spreng et al., 1996).

EDT predicts that, in theory, continued usage intention depends on the degree of satisfaction and confirmation (Bhattacherjee, 2001; Lin et al., 2005). First, users form initial expectations of a specific service or technology prior to adoption, after which they compare their perceptions of its performance with their prior expectations and determine the extent to which their expectations were confirmed. They thus form a feeling of satisfaction or dissatisfaction based on the degree of their confirmation or disconfirmation. Finally, satisfied users form intentions to reuse the service or technology in the future (Anderson et al., 1994; Bearden et al., 1983; Churchill et al., 1982; Fornell et al., 1984; Oliver, 1980; Oliver et al., 1981; Yi, 1990). 
Thus, EDT suggests that users' continuance intention is determined by satisfaction. Igbaria, and Tan (1997) similarly found that satisfaction is a major determinant of continued usage. Bokhari (2005) performed a meta-analysis and empirically validated a positive relationship between satisfaction and system usage. Satisfaction may thus be a determining factor in the user's intention to continue using a technology, due to the positive reinforcement of his or her attitude toward the technology. Therefore, we propose the following hypotheses:

H1. Confirmation has a positive influence on user satisfaction.

H2. Confirmation has a positive influence on CUI.

H3. User satisfaction has a positive influence on CUI.

As suggested by Ling \& Yttri (2002), user satisfaction with a smart mobile device is influenced by the device's quality, which in turn, depends on its response time, ease of use (Swanson, 1974), accuracy, reliability, completeness, and flexibility (Hamilton and Chervany, 1981). Seddon (1997) employed the IS Success Model (DeLone and McLean, 1992) and found that system quality is positively related to satisfaction (Dourish, 2001). The IS Literature (VanDyke et al., 1997) shows that system quality promotes user satisfaction in the marketing field (Collier and Bienstock, 2006). Thus, we have the following hypotheses:

H4. The system quality of a smart mobile device has a positive influence on the satisfaction of its user.

H5. The system quality of a smart mobile device has a positive influence on its user's CUI.

Kakihara and Sorensen (2002), Green (2002), Sorensen and Taitoon (2008), Boase and Kobayashi (2008), Chatterjee et al., (2009), and LaRue et al., (2010) investigated mobility along four dimensions: spatial, temporal, contextual, and social fluidity. the current study investigates the perceived performance of smart mobile devices in terms of these four dimensions and how their performance affects users' confirmation and satisfaction of using a mobile device.

Spatial mobility denotes physical movement, which is the most immediate aspect of mobility (Ling and Yttri, 2002). Spatial mobility refers not only to the extensive geographical movement of people, but also signifies the global flux of objects, symbols, and space itself, and as such evokes complex patterns of human interaction (Kakihara and Sørensen 2002). The rapid diffusion of ICT in general and mobile communication technologies-particularly smart mobile phoneshas further energized human geographical movement, or nomadicity, in urban life, work environments, and many other societal milieus (Dahlbom, 2000; Chatterjee et al., 2009). Furthermore, devices that combine a GPS sensor, Internet access via a $3 \mathrm{G}$ or $4 \mathrm{G}$ network, and a digital camera enable users to integrate spatiality into their daily lives (Egenhofer, 1998). Location-aware applications, such as google maps, help users position where they are and identify nearby resources e.g. banks and restaurants. Thus, smart mobile devices are more likely to be used in situations where users experience a high degree of spatial mobility, and are likely to increase the satisfaction of these users. Therefore, we hypothesize that:

H6a: Spatial mobility has a positive influence on confirmation after usage of a smart mobile device.

H7a: Spatial mobility has a positive influence on user satisfaction after usage of a smart mobile device.

Temporal mobility denotes the flexibility of task scheduling and coordination under different situations (Ling and Yttri, 2002). Some studies (for example, Barley, 1988) suggest that changes in work orders are enabled by information and communication technologies. Barley (1988) characterizes temporal mobility using the dichotomy of monochronicity and polychronicity. Monochronicity refers to situations in which people seek to structure their activities and plan for events by allocating specific slots of time to each event's occurrence, whereas polychronicity 
refers to situations in which people place less value on the divergence of structural and interpretive attributes of the temporal order.

Short message system (SMS), google calendar and other mobile applications on scheduling, using push technology found in most smart mobile devices, remind users of the latest appointments on their online calendars, allowing them to deal with multiple tasks simultaneously. ICTs allow information and ideas to be instantaneously transmitted and simultaneously accessed across the globe (Urry, 2000). Thus, it can be argued that such "instantaneity" of time in contemporary society and cyberspace further increases the polychronicity of human activities, which can no longer be restricted by a linear "clock-time" perspective. Human interactions are now highly mobilized into multiple temporal modes depending on users" perspectives and their interpretation of time. This situation leads to a complex social environment where the polychronicity of interaction among humans is intertwined (Kakihara and Sørensen, 2002) and performing multiple tasks simultaneously becomes possible (Datamonitor, 2000; May, 2001).

Temporal mobility implies that people can deliver or receive time-sensitive information at their mobile devices (Tsalgatidou and Pitoura, 2001). Time-critical situations where immediacy is essential, or at least desirable, typically arise from external events. Hence, the always-on connectivity of smart mobile devices is important for resolving these situations. On-demand pushtechnological solutions (alerts and reminders) allow users to handle time-critical events. Thus, we hypothesize that:

H6b: Temporal mobility has a positive influence on confirmation after usage of a smart mobile device.

H7b: Temporal mobility has a positive influence on user satisfaction after usage of a smart mobile device.

People's behaviors are inherently situated in a particular context that frames, and is recursively reframed by, their interactions with the environment (Kakihara and Sørensen, 2002). Contextual mobility, which refers to the ability to capture information of a situation dynamically and react accordingly, is critical for humans responding to different interactional aspects such as "in what way," "in what particular circumstance," and "toward which actor(s)". Context-aware applications, such as weather apps, inform users of current temperature and weather conditions in the district where he or she is situated. This contextual feature of mobile devices is highly valuable and tremendously increases usability (Baldauf, 2007).

Mobile devices such as Blackberrys are developed to increase users' productivity by providing contextual information (Peters, 2002). People constantly look for more efficient and dynamic ways of carrying out business activities (Kalakota and Robinson, 2001). The chief benefit of portable computing devices lies in increasing workers' productivity, as businesspeople who can check their schedules and access corporate information as needed are more efficient than their competitors who have to call their offices continually (Delichte, 2001; Maginnis et al., 2000). The contextuality of smart mobile devices helps improve users' efficiency, and therefore enhances their confirmation of, and satisfaction with, their mobile phones. In sum of the above arguments, we have the following hypotheses:

H6c: Contextual mobility has a positive influence on confirmation after usage of a smart mobile device.

H7c: Contextual mobility has a positive influence on user satisfaction after usage of a smart mobile device.

Social mobility signifies the dynamic interaction among users (Dourish, 2001). Nowadays, most smart mobile devices like the iPhone 5 or the Samsung Galaxy Note II have incorporated 
common means of communication, such as email, Skype, instant messaging, Facebook, Twitter, and SMS to facilitate connectivity among users. Due to their portability and "person-to-person" connectivity capability, mobile phones have facilitated a cultural shift from maintaining strong ties to maintaining weak ones. The mobility of mobile phones frees people from physical confines (Adam, 1995; Cairncross, 1997). It also facilitates interactions with diverse social ties, accelerating the rise of networked individualism (Haythornthwaite and Wellman, 2002; Wellman, 2001; Wellman, 2002). A study by Kopomaa (2000) shows that mobile phones affect urban society because family members coordinate their lives using mobile phones (Ling, 1999a, b; Ling and Yttri, 2002). Based on these benefits, we hypothesize that:

H6d: Social mobility has a positive influence on confirmation after usage of a smart mobile device.

H7d: Social mobility has a positive influence on user satisfaction after usage of a smart mobile device.

\subsection{Control Variables}

The backgrounds of users may influence CUI (Chiasson and Lovato, 2001). Prior experience, for example, may be proportionate to confirmation (Rosson, Carroll and Rodi, 2004). The education of users sometimes increases with their understanding of mobile devices. Different levels of understanding result in different presumptions, influencing user confirmation. Therefore, it was necessary to control the possible effects of gender, age, prior experience, and education on CUI.

\subsection{Data Collection}

Given the research objectives, we adopted a survey approach as the research method. We developed a survey instrument to collect quantitative data for model and hypothesis testing. Recommendations from five IS experts and two management information system (MIS) professors were incorporated to improve the instrument. A pilot study was conducted to further evaluate the instrument. The population of this survey included individuals with experience in using pocket PC mobile phones. Appendix A lists the measurement items. The questionnaire consisted of 26 items to assess the seven constructs of our proposed theoretical model: spatial mobility (Spt), temporal mobility (Tmp), contextual mobility (Cnt), social fluid mobility (SFl), system quality (SQ), user satisfaction (USat), confirmation (Conf), and CUI. The first four constructs-Spt, Tmp, Cnt, and SFl, consisting of 14 items-were mainly operationalized from studies by Kakihara and Sørensen (2002) and Chatterjee et al., (2009). USat was measured using four items adopted from studies by Oliver (1980) and Spreng and Chiou (2002). CUI, which consisted of four items, was measured by using the scale recommended by Agarwal and Prasad (1997). All the constructs were measured on a seven-point Likert scale, ranging from (1) "strongly agree" to (7) "strongly disagree." Some demographic data regarding age, gender, and level of education were collected at the end of the questionnaire.

\section{CONCLUSIONS}

There are various limitations in this study. This study viewed continued usage as an extension of acceptance behaviors (that is, they employed the same set of pre-acceptance variables to explain both acceptance and continued usage), and implicitly assumed that continued usage goes together with technology acceptance (for example, Davis et al., 1989; Karahanna et al., 1999). We were therefore unable to explain why some users discontinue IT/IS use after initially accepting it (that is, the acceptance-discontinuance anomaly). 
User-based research and development strategy suggests that vendor services and products have to meet users' expectations. In this regard, field surveys are an important means for mobile device manufacturers to address the principal focus of the users. Different users may demonstrate similar preferences for the same mobile application.

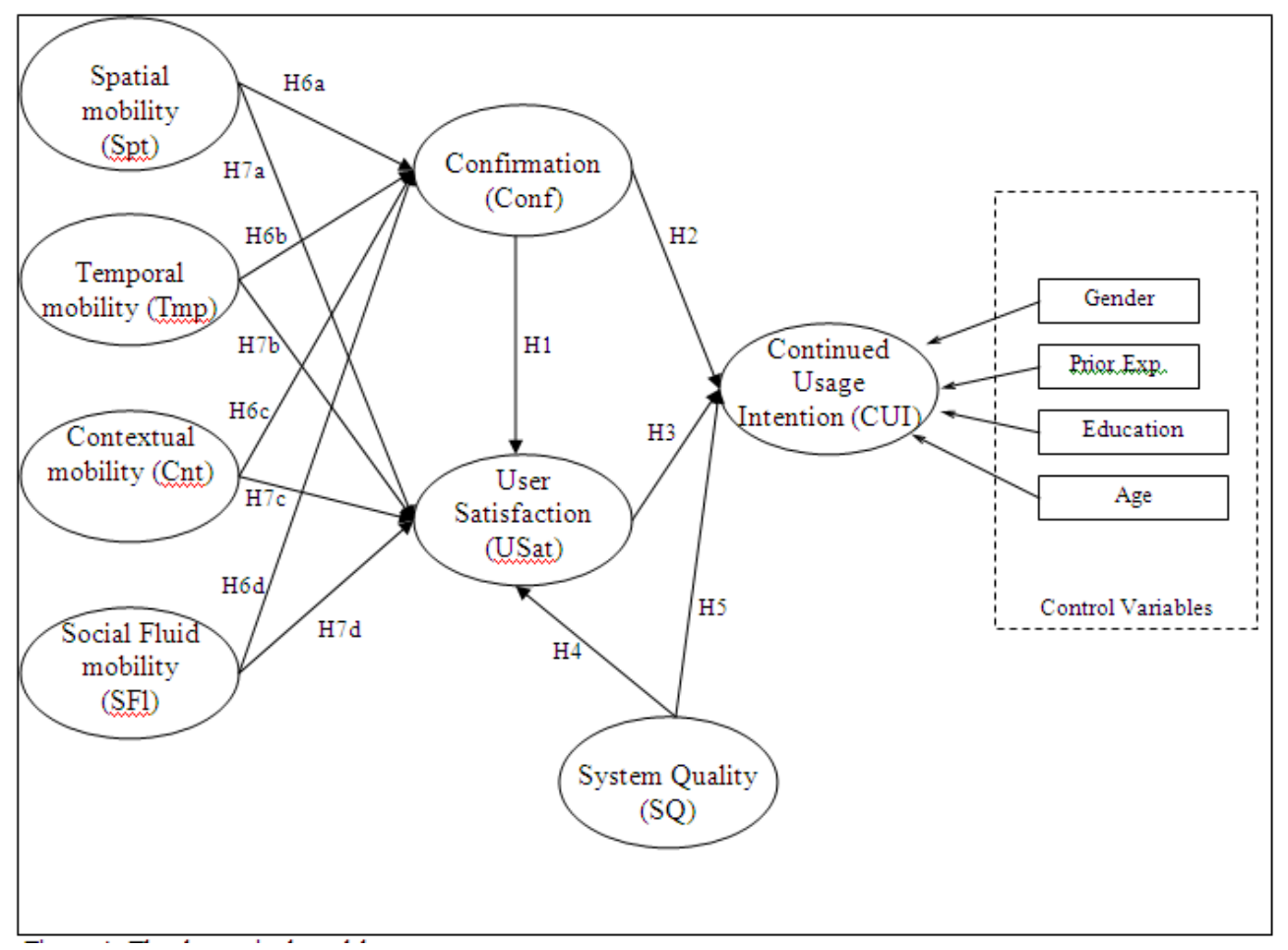

Figure 1: The theoretical model

\section{REFERENCES}

[1] Adam, B. (1995). Timewatch. Cambridge: Polity Press.

[2] Anderson, E.W., Fornell, C., and Lehmann, D. (1994). Customer Satisfaction, Market Share, and Profitability: Findings from Sweden. Journal of Marketing, 58, 53-66.

[3] Baldauf, M. (2007). A survey on context-aware systems. Int. J. Ad Hoc and D Ubiquitous Computing, 2 (4), 263-277.

[4] Barley, S.R. (1988). On Technology, Time, and Social Order: Technically Induced Change in the Temporal Organization of Radiological Work, in F.A. Dubinskas ed. Making Time: Ethnographies of High-Technology Organizations, Philadelphia, PA: Temple University Press.

[5] Bearden, W.O., and Teel, J.E. (1983). Selected Determinants of Consumer Satisfaction and Complaint Reports, Journal of Marketing Research, 20, 21-28.

[6] Bhattacherjee, A. (2001). Understanding Information Systems Continuance: An ExpectationConfirmation Model, MIS Quarterly, 25(3), 351-370.

[7] Cairncross, F. (1997). The Death of Distance: How the Communications Revolution Will Change Our Lives. Boston: Harvard University Business School Press.

[8] Chatterjee S., Chakraborty S., Sarker S., Sarker S., and Lau F., (2009). Examining the success factors for mobile work in healthcare: a deductive study. Decision Support Systems, 46, 620 - 633.

[9] Chiasson, M. W. and Lovato, C. Y. (2001). Factors Influencing the Formation of a User's Perceptions and Use of a DSS Software Innovation. The DATA BASE for Advances in Information Systems, 32 (3), 16-35.

[10] Churchill, G.A., and Surprenant, C. (1982). An Investigation into the Determinants of Customer Satisfaction. Journal of marketing Research, 24, 305-314. 
[11] Cooper, R. B., and Zmud, R. W. (1990). Information Technology Implementation Research: A Technological Diffusion Approach. Management Science 36 (2), 123-139.

[12] Dahlbom, B. (2000). Networking: From Infrastructure to Networking. in K. Braa, C. Sorensen, and B. Dahlbom eds., Planet Internet, Lund: Studentlitteratur, 2000, pp.217-238

[13] Davis, F. D. (1989). Perceived usefulness, perceived ease of use, and user acceptance of information technology. MIS Quarterly, 13(3), 319-340.

[14] Dourish, P. (2001). Seeking a foundation for context-aware computing. Hum-Comput Interact, 1, 229241

[15] Egenhofer, M. J. (1998). Spatial Information Appliances: A Next Generation of Geographic Information Systems. National Center for Geographic Information and Anlaysis.

[16] Egenhofer, M. J. (2000). Spatial Information Appliances: A Next Generation of Geographic Information Systems. National Science Foundation.

[17] Fornell, C., and Westbrook, R.A. (1984). The Vicious Circle of Consumer Complaints. Journal of Marketing, 56, 6-21.

[18] Haney, L. (2005). Contextual and Cultural Challenges for User Mobility Research. Communications of the ACM, 48 (7). $7-41$.

[19] Haythornthwaite, C. and Wellman. B. (2002). The Internet and Everyday Life: An Introduction. In The Internet and Everyday Life. Edited by B. Wellman and C. Haythornthwaite. Blackwell Publishing.

[20] Kakihara, M. and Sorensen, C. (2002). Mobility: An Extended Perspective. Proceedings of the 35th Hawaii International Conference on System Sciences, 1756 - 1766.

[21] Kakikara, M. and Sorensen, C.. (2004). Practising mobile professional work: tales of locational, operational, and interactional mobility. Journal of policy, regulation and strategy for telecommunications, information and media, 6 (3), 180-187.

[22] Kopomaa, T. (2000) The city in your pocket: Birth of the mobile information society. Gaudeamus: Tampere, Finland.

[23] Kwon, T. H. and Zmud, R. W. (1987). Unifying the Fragmented Models of Information Systems Implementation.Critical. Information Systems Research, R. J. Boland and R. A. Hirschheim (eds.), John Wiley and Sons, New York, 227-251.

[24] Lee, K. C. Kang, I. and Kim, J. S. (2007). Exploring the user interface of negotiation support systems from the user acceptance perspective. Computers in Human Behavior, 23, 220-239.

[25] Ling, R. and Yttri, B. (2002). Nobody sits at home and waits for the telephone to ring: Micro and hyper-coordination through the use of the mobile telephone. In J. Katz and M. Aakhus (eds) Perpetual contact: Mobile communication, private talk, public performance, Cambridge University Press, Cambridge.

[26] Ling, R. (1999a) We release them little by little: maturation and gender identity as seen in the use of mobile telephony. Telenor RandD Report 5/99, Kjeller, Norway.

[27] Locke, E. A. (1976). The Nature and Causes of Job Satisfaction. Handbook of Industrial and Organizational Psychology, Holt, Reinhart and Winston, New York, 1297-1349.

[29] Oliver, R. L. (1981). Measurement and Evaluation of Satisfaction Processes in Retail Settings. Journal of Retailing, 57(3), 25-48.

[30] Oliver, R.L. (1980). A Cognitive Model of the Antecedents and Consequences of Satisfaction Decisions. Journal of marketing Research, 17, 460-469.

[31] Oliver, R.L., and Linder, G. (1981). Effect of Satisfaction and its Antecedents on Consumer Preference and Intention. Advances in Consumer Research, 8, 88-93.

[32] Premkumar, G. and Bhattacherjee, A. (2008). Explaining Information Systems Usage: A Test of Competing Models. Omega - The International Journal of Management Science, 36(1), 64-75.

[33] Rogers, E. M. (1995). Diffusion of Innovations (4th ed.), Free Press, New York.

[34] Rosson, M. B. Carroll, J. M. and Rodi, C. M. (2004). Case Studies for Teaching Usability Engineering. ACM.

[35] Hamilton, S. and Chervany, N.L. (1981). Evaluating information system effectiveness. I. Comparing evaluation approaches, MIS Quarterly 5 (3), 1981, pp. 55-69.

[36] Swanson E.B. (1974). Management information systems: appreciation and involvement, Management Science 21 (2), 178-188.

[37] Urry, J. (2000). Sociology beyond Societies: Mobilities for the Twenty-First Century, London: Routledge.

[38] Wixom B.H., Todd P.A. (2005). A Theoretical Integration of User Satisfaction and Technology Acceptance, 16(1) 85-102. 
[39] Zmud, R. W. (1982). Diffusion of Modern Software Practices: Influence of Centralization and Formalization. Management Science, 25 (10), 966-979.

\section{AUTHORS}

\section{Vincent Cho}

Vincent Cho is an associate Professor in the Department of Management and Marketing, The Hong Kong Polytechnic University. He obtained his $\mathrm{PhD}$ from the Hong Kong University of Science an d Technology. His teaching interests are MIS, e-commerce and IT strategies. His research interests lie with social media influence, technology adoption, and data mining.

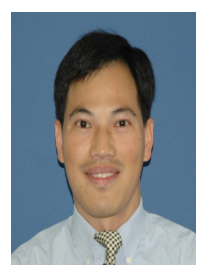

\section{Eric WT Ngai}

Eric W. T. Ngai, PhD, is a Professor in the Department of Management at The Hong Kong Polytechnic University. His current interests include electronic commerce, Web/EDI-based supply chain $\mathrm{m}$ anagement systems, decision support systems and expert systems.

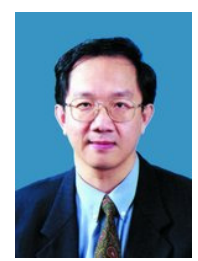

